\title{
Teaching about speech perception and production inexpensively on microcomputers
}

\author{
JOSEPH P. BLOUNT \\ Saint Mary's College, Notre Dame, Indiana \\ and \\ MARY ANN R. BLOUNT \\ Saint Joseph's Medical Center, South Bend, Indiana
}

\begin{abstract}
It is difficult to teach an introduction to speech perception and production without hands-on experience for the students. We suggest inexpensive ways to use microcomputers to give such experience, with regard to letter-to-sound correspondences, formants, voice onset time, and other topics. Students have reported that they learn more with these approaches and enjoy them.
\end{abstract}

Speech perception and production is an area of science in which there has recently been rapid, exciting progress. Psychologists, linguists, and others have discovered astonishing new perceptual phenomena and begun to unravel the complexity of the acoustic coding. Because of the usefulness and importance of the principles, an introduction to them is now often included in cognitive psychology courses, sensation and perception courses, psychology of language courses, a few introductory psychology courses, speech science courses, hearing science courses, other courses in communication disorders departments, a number of courses in linguistics departments, and elsewhere. (Some examples of texts that include these topics are: Bernstein, Roy, Srull, \& Wickens, 1988; Best, 1989; and Glass \& Holyoak, 1986).

We have encountered some problems in trying to teach such subject matter. Beginning students lack motivation, because the topics seem prescriptive, boring, and nonintuitive. Even those with more interest have difficulty understanding, because many principles seem untrue in terms of everyday experience and it is hard to imagine from written descriptions what the stimuli and experiments are like.

The purpose of this paper is to suggest several related solutions and to report qualitatively on student responses to these approaches. We hope to show both novice and experienced computer users interesting, beneficial ways in which computers can be used in teaching and to inspire them to invent more uses on their own. Recent advances in computer software and hardware have made available for prices from a few dollars to a few thousand tools that used to cost researchers over $\$ 100,000$. This means that teachers can provide live demonstrations and allow students hands-on learning that was unavailable even 2 years ago. A comprehensive survey of such programs

Correspondence may be addressed to Joseph P. Blount, Department of Psychology, Saint Mary's College, Notre Dame, IN 46556. or equipment is beyond the scope of this paper; however, we do sample from products involved in speech production as well as perception, from products for Macintosh as well as IBM-compatible systems, and from competing products as well.

In the remainder of this paper, we will discuss nine learning activities and the software or equipment that makes them easy to accomplish. The first activity is intended to show the students that they already know more about speech than they realize. Later activities are both more humbling and more surprising; they show that instruments can reveal a lot about speech acoustics that everyday experience cannot. Some of the exercises we have explored, but not tested in class. These are included in the numbered sequence of sections below, but they are labeled as "ideas" rather than activities. Identifying information about computer software and hardware is included in the Appendix.

\section{Activity 1: Letter-to-Sound Correspondences}

In English, letter-to-sound correspondences are complex. Introductory students can discover a lot about this complexity by reflectively thinking and then testing their hunches on a text-to-speech synthesizer, such as MacinTalk. Students may not be aware of the different methods behind synthesis and digitized playback. The difference is as easy to understand as the difference between making a cake from scratch and using a mix. This activity focuses on synthesis. For example, the teacher could start the exercise by demonstrating some one-toone correspondences (e.g., the letters $c$ and $k$ both correspond to the $/ \mathrm{k} /$ sound). At this point, students will often volunteer the fact that different spellings produce the same sound (e.g., the vowels in eye and sight). The teacher needs to point out that the computer takes into account subtle differences in what the layperson might think of as one sound (e.g., the initial vowels in digest, sight, site, and dye have four different phonemic transcriptions in MacinTalk). Furthermore, the computer rules must take 
context into account (the sound of the letter $t$ in the word tee vs. $t$ in the). In spite of this sophistication, there are (many) words the computer mispronounces (e.g., MacinTalk has trouble with fliers, negative, etc.). The teacher can challenge the students to identify some other words that they think the computer will mispronounce. Common student responses include proper names (their own), long words, and generalizations from the examples provided by the teacher (in parallel with the examples above: pliers, aggressive, etc.). Teachers can prepare a list of words that they know the computer will mispronounce; it is then fun to have students try to predict how specific words will sound on the computer. What would you predict for doughnut? Students can be asked to invent nonstandard spellings that will lead the computer to correct pronunciations. What do you think the computer will say for ghoti? Given that ghoti is George Bernard Shaw's famous nonstandard spelling of fish, why doesn't the computer pronounce it fish? (The gh in enough is pronounced /f/, but that is an exception to the usual letterto-sound correspondence, etc.) Linguistically sophisticated students may like to try to infer some of the rules the computer is using. In one class, students spontaneously named this the most exciting demonstration of the semester.

Synthesis can also be based on graphically specified formants (historically, the Pattern Playback machine), numerically specified formants, or articulatory movements (very nicely explained and demonstrated in HyperASY1.1).

\section{Activity 2: Sequences of Sound Units}

The acoustic stream cannot be decomposed into a sequence of sound units the way text can be decomposed into a sequence of letters. This undecomposability can easily be seen in an oscilloscope waveform that allows selection and playback of subparts (as with the program MacRecorder; it can also be shown in spectrograms, as with MacSpeech Lab or Micro Speech Lab). Students can try to slice up a phrase, such as paperback writer, into units for each letter and record what percentage of the units sounds like the targeted letter, what percentage sounds like thuds, clicks, whistles, chirps, and so forth.

\section{Activity 3: Acoustic Silence versus \\ Perceived Silence}

Contrary to common sense, acoustic silence and perceived silence are not the same thing. We hear speech as if there were silent gaps between noiseful words, but acoustic analyses reveal many gaps actually to be noiseful. Such analyses also reveal within-word silences. Students can find examples of within-word silences and noiseful gaps using an oscilloscope waveform (or a digital spectrogram). For example, the word speaking has silence between the /s/ sound and the first vowel. Curting out the silence transforms it into seeking. (Caution: if the speaker aspirates the $/ p /$, it may be impossible to remove it.)

\section{Idea 4: Formants}

Any segment of speech involves several concentrations of acoustic energy at several frequencies. The relative separations of the energy bands are important for identifying steady-state vowels, but the absolute frequency levels of the formants are not important. Students can synthesize (e.g., in MacSynth) several /a/ sounds at high and low frequencies and contrast these with several /e/ sounds. Alternately, students can analyze human tokens of these sounds. Differences in pitch are poor approximations to the differences among men, women, and children.

\section{Idea 5: Transitions}

Patterns of change among the formants can carry information. Students can spectrally analyze their own ba-da-ga/bee-dee-gee syllables by looking for what is common to the two $b s, d s$, and $g s$ (energy transitions in the formants). (For this, use MacSpeech Lab software with MacAdios hardware.) One goal of this exercise is to reveal that some speakers show nice formants, whereas others do not. The teacher may need samples of "clean voices" for students who cannot use their own voices.

\section{Activity 6: Synthetic versus Natural Speech}

Formants are something of an idealization; they cannot account for all the qualities of the human voice. Students can compare their own voices with a synthesized voice, first for intelligibility and naturalness, as judged by listeners (Klatt, 1987), and then spectrographically, for similar formant frequencies and transitions, voice onset time, and so forth. Formant patterns that look the best often do not sound the best! (MacinTalk and MacSpeech Lab with MacAdios are sufficient for this exercise. DecTalk produces much more accurate and intelligible synthetic speech than MacinTalk does; if available, DecTalk makes for a more interesting comparison with humans, and a delightful contrast with MacinTalk. In variations of this exercise, students might compare their normal speech to speech with an obstruction in their mouths, or they might analyze highly accelerated speech, such as that of radio personality Ian Shoales.) Students found this exercise enjoyable, a beneficial learning experience, and worth recommending to future classes.

\section{Idea 7: Parallel Transmission}

The acoustic stream involves parallel transmission; in particular, different frequencies can carry different information simultaneously. One example: Do the high or low frequencies in a blackboard scratch or monkey howl cause us to shudder (Halpern, Blake, \& Hillenbrand, 1986)? Students can listen to such stimuli whole, then digitally break them into "high" and "low" halves to hear what each half sounds like. (MacRecorder, for example, does high/low filtering; MacSpeech Lab spectrograms show high- and low-frequency energy.) In this case, our intuitions (high) are wrong! Another example: Individual for- 
mants do not sound like notes summing to a chord; rather, they seem to be nonspeech sounds unrelated to the vowel of which they are a part. A third example might be to substitute silence for a "vowel" and find that the vowel is still perceptible-because what was called the "consonant" is transmitting information in parallel about the vowel (Jenkins, Strange, \& Edman, 1983).

\section{Activity 8: Categorical Perception}

Unlike the shades of a color that are perceived as matters of degree, shades of acoustic timing are perceived as categorically different speech sounds. First, the students can listen to and judge stimuli from, say, a standard $/ \mathrm{ba} /-/ \mathrm{pa} /$ continuum. (We do not know of a simple way to generate one's own continuum; however, we have found workers in the field of speech perception very generous in providing us with tape-recorded samples.) There should be two perceptual tasks: identification (labeling each syllable) and discrimination (presenting, say, three syllables and judging whether the third was the same as the first or second). Next, the students can tabulate and graph their data to discover that labeling switches suddenly rather than gradually, and that it does so at the same point as that at which discrimination peaks-that is to say, perception is categorical. Then, for a contrast, they can view voice onset time on a digital spectrogram (such as MacSpeech Lab software with MacAdios hardware) and see that the physical dimension is continuous. In scaled responses, our students "agreed" that this was an enjoyable exercise and a beneficial learning experience, and they recommend it for future classes. They only "somewhat agreed" that it helped them understand identification and discrimination. It seems that they would need more discussion than we had provided, were they to re- late the theory to the experimental methodology. In introductory classes for nonprofessionals, the discrimination task could be omitted.

\section{Idea 9: Top-Down Processing}

Speech must involve top-down (as well as bottom-up) processing. Students can listen to dash of salt/task before us and report that the initial $/ \mathrm{t} /$ and $/ \mathrm{d} /$ sound perceptually different. Then they can spectrally analyze the $/ t /$ and $/ d /$ and show that they are acoustically the same. (Caution: Some speakers make the $/ \mathrm{t} /$ and $/ \mathrm{d} /$ distinct.) The two phonemes can be guaranteed identical by splicing (with MacRecorder) identical tokens in the two phrases.

In summary, many central principles of speech perception and production can be made concretely available to students in demonstrations or laboratory exercises. The examples that students generate on microcomputers may not be of as high a quality as those selected by professionals and produced on more expensive instruments; nonetheless, such examples are sufficient for lively demonstrations of speech science. The hands-on manipulation provides students with an exciting learning experience.

\section{REFERENCES}

Bernstein, D. A., Roy, E. J., Srull, T. K., \& Wickens, C. D. (1988). Psychology. Boston: Houghton Mifflin.

Best, J. B. (1989). Cognitive psychology (2d ed.). St. Paul, MN: West. Glass, A. L., \& Holyoak, K. J. (1986). Cognition (2d ed.). New York: Random House.

Halpern, D. L., Blake, R., Hillenbrand, J. (1986). Psychoacoustics of a chilling sound. Perception \& Psychophysics, 39, 77-80.

Jenkins, J. I., Strange, W., \& Edman, T. R. (1983). Identification of vowels in "vowelless" syllables. Perception \& Psychophysics, 34, 441-450.

KLATT, D. H. (1987). Review of text-to-speech conversion for English. Joumal of the Acoustical Society of America, 82, 737-793.

\begin{tabular}{|c|c|c|}
\hline \multicolumn{3}{|c|}{$\begin{array}{l}\text { APPENDIX } \\
\text { Computer Software and Hardware for Speech Perception and Production }\end{array}$} \\
\hline Name & Source & Description (Macintosh unless noted) \\
\hline MacinTalk & public domain & $\begin{array}{l}\text { Low quality, but real-time text-to- } \\
\text { speech synthesis with nonstandard } \\
\text { phonetic "alphabet." }\end{array}$ \\
\hline MacSynth & $\begin{array}{l}\text { Dr. Peter Ladefoged } \\
\text { UCLA Phonetics Lab }\end{array}$ & $\begin{array}{l}\text { Limited speech synthesis from } \\
\text { formant specifications. }\end{array}$ \\
\hline $\begin{array}{l}\text { HyperASY } 1.1 \\
\text { \& WAG }\end{array}$ & $\begin{array}{l}\text { Philip Rubin } \\
\text { Haskins Laboratories } \\
\text { (203) } 865-6163\end{array}$ & $\begin{array}{l}\text { Hypercard stacks that demonstrate } \\
\text { articulatory synthesis, a talking first } \\
\text { and second formant space, etc. }\end{array}$ \\
\hline MacRecorder & $\begin{array}{l}\text { Farallon } \\
\$ 249 \text { list } \\
(415) 849-2331\end{array}$ & $\begin{array}{l}\text { Hardware and software combination; } \\
\text { record/digitize, compress, playback, } \\
\text { and edit oscilloscope waveforms. }\end{array}$ \\
\hline SoundWave & $\begin{array}{l}\text { Impulse Inc. } \\
6870 \text { Shingle Creek Pkwy. } \\
\# 112 \\
\text { Minneapolis, MN } 55430\end{array}$ & $\begin{array}{l}\text { Record, playback, and edit } \\
\text { waveforms. }\end{array}$ \\
\hline
\end{tabular}


APPENDIX (Continued)

\begin{tabular}{|c|c|c|}
\hline Name & Source & Description (Macintosh unless noted) \\
\hline MacSpeech Lab & $\begin{array}{l}\text { GW Instruments } \\
\$ 300 \\
(617) 625-4096\end{array}$ & $\begin{array}{l}\text { Edit oscilloscope waveforms, display } \\
\text { spectrograms, and power spectra. }\end{array}$ \\
\hline MacAdios & $\begin{array}{l}\text { GW Instruments } \\
\$ 2,500\end{array}$ & $\begin{array}{l}\text { Companion hardware: analog/digital } \\
\text { input/output system. }\end{array}$ \\
\hline Sound Designer & $\begin{array}{l}\text { Digidesign } \\
(800) 333-2137\end{array}$ & $\begin{array}{l}\text { Playback and edit amplitude } \\
\text { envelopes, power spectra, etc. }\end{array}$ \\
\hline $\begin{array}{l}\text { Micro Speech Lab } \\
\text { PC-compatibles }\end{array}$ & $\begin{array}{l}\text { SRC Software } \\
\$ 1,600 \\
(604) 727-3744 \\
\text { (also available through } \\
\text { Kay Elemetrics) }\end{array}$ & $\begin{array}{l}\text { Hardware/software combination; } \\
\text { record, playback, and edit } \\
\text { waveforms; energy and pitch } \\
\text { contours, smoothed power spectra. }\end{array}$ \\
\hline
\end{tabular}

